\title{
Localized damage response of carbon fiber reinforced polymer composite sandwich panel after thermal exposure
}

\author{
Jiayi Liu ${ }^{\mathrm{a}, \mathrm{b}}$, Tao Kan ${ }^{\mathrm{a}}$, Jia Lou ${ }^{\mathrm{c}}$, Linling Xiang ${ }^{\mathrm{a}}$, Xiang Zhu, ${ }^{\mathrm{a}, *}$, Yongsheng Tang ${ }^{\mathrm{b}}$ \\ ${ }^{a}$ School of Naval Architecture and Ocean Engineering, Huazhong University of \\ Science and Technology, Wuhan 430074, PR China \\ ${ }^{\mathrm{b}}$ Hudong-Zhonghua Shipbuilding(Group) Co., Ltd, Shanghai 200129, PR China \\ 'Piezoelectric Device Laboratory, Department of Mechanics and Engineering Science, \\ Ningbo University, Ningbo, Zhejiang 315211, PR China
}

\begin{abstract}
An experimental study was conducted to investigate the effect of thermal exposure on indentation behaviors of carbon fiber reinforced polymer composite sandwich panel (CFRPCSP) with pyramidal truss cores. Composite sandwich panels were fabricated by the hot press molding method. Subsequently, composite sandwich panels were exposed to different temperatures for $6 \mathrm{~h}$. After thermal exposure, quasi-static indentation tests were carried out at room temperature. Then, the effect of thermal exposure on the failure mechanism, indentation load and energy absorption were analyzed and discussed. The results showed that the indentation load and energy absorption decreased as exposure temperature increased, which was caused by the degradation of the matrix properties and fiber-matrix interface properties at high temperature. In addition to the decreasing of the indentation load and energy absorption, the failure modes also changed with exposure temperature. It is expected that this study can provide useful information for the design and application of composite sandwich panel with pyramidal truss cores at high temperature.
\end{abstract}

Keywords: Composite; Sandwich panel; Indentation behaviors; Thermal exposure.

\footnotetext{
${ }^{*}$ Corresponding author at: School of Naval Architecture and Ocean Engineering, Huazhong University of Science and Technology, Wuhan 430074, PR China.

E-mail address: zhuxiang@ @ust.edu.cn (Xiang Zhu).
} 


\section{Introduction}

Fiber reinforced polymer composite sandwich panel (FRPCSP) with lattice truss cores are increasingly used in aerospace and shipping industry, which have been designed and fabricated during the last decade [1-6]. Their mechanical behaviors have been tested and analyzed at room temperature, and the superior mechanical properties have been revealed [7-10]. Fan et al. [11] investigated the compressive and bending behaviors of carbon fiber reinforced polymer composite sandwich panel (CFRPCSP). They found that debonding failure dominated the mechanical behavior of composite sandwich panel with stiff skins. Sun et al. [12] studied the compressive and shear properties of CFRPCSP with pyramidal truss cores. Xiong et al. [13] investigated the crushing response of CFRPCSP with pyramidal truss cores. The results showed that the low-density truss cores have superior mechanical properties, which can be used for novel lightweight multifunctional structures. However, these studies were mainly focused on the failure and strength of CFRPCSP at room temperature. They did not investigate the mechanical behaviors of CFRPCSP after exposure to high temperature.

FRPCSP was quite sensitive to temperature variation. The mechanical properties experienced severe degradation when they were exposed to high temperature [14-16]. Currently, some scholars have studied the mechanical behaviors of composite laminates after thermal exposure. They found that the mechanical properties and failure modes changed with exposure temperature [17-19]. Furthermore, the mass loss, delamination damage and matrix decomposition have also been found during testing [20-23]. Foster et al. [19] studied the residual tensile strength of fiber reinforced polymer (FRP) composite materials after exposure to $100^{\circ} \mathrm{C}, 200^{\circ} \mathrm{C}, 300^{\circ} \mathrm{C}$ and $400^{\circ} \mathrm{C}$ for $3 \mathrm{~h}$. The results indicated that the residual tensile strength experienced severe reduction at $400^{\circ} \mathrm{C}$. Cleary et al. [24] investigated the effect of thermal exposure on the residual compressive strength of FRP-confined concrete cylinders. They found that FRP-confined concrete cylinders lost about 2\%, 4\%, 13\% and 18\% of the initial ultimate strength after exposure to $120^{\circ} \mathrm{C}, 135^{\circ} \mathrm{C}, 150^{\circ} \mathrm{C}$ and $180^{\circ} \mathrm{C}$ for 90 min. Although several studies have reported the residual mechanical properties of 
composite laminates after thermal exposure, while less is known about the structural integrity of CFRPCSP with pyramidal truss cores after thermal exposure. Thus, further work is required to fill the gaps in knowledge.

The present study aims to reveal the effect of thermal exposure on indentation behaviors and failure mechanism of CFRPCSP with pyramidal truss cores. Composite sandwich panels were exposed to different temperatures for $6 \mathrm{~h}$. After thermal exposure, quasi-static indentation tests were performed at room temperature. Then, the effect of thermal exposure on indentation behavior and failure mechanism were discussed and analyzed.

\section{Fabrication}

CFRPCSP with pyramidal truss cores were fabricated by the hot press molding method. The details of the manufacturing process are as follows. Firstly, the unidirectional carbon/epoxy prepregs were cut to the required size and then used to form composite struts. Secondly, the unit molds were assembled into the completed mold, and composite struts were inserted into the holes of the molds, as shown in Fig. 1(a). In order to simplify the demoulding process, the unit mold was divided into three parts. Thirdly, the carbon/epoxy prepregs were laid on the surface of the molds, and the ends of composite struts were dispersed and embedded gradually in the mid-plane of the face sheet, as shown in Fig. 1(b). Finally, the preformed sandwich panel were cured at $125^{\circ} \mathrm{C}$ under pressure of $0.5 \mathrm{MPa}$ for $1.5 \mathrm{~h}$, as shown in Fig. 1(c). After curing, the molds were removed from composite sandwich panel, as shown in Fig. 1(d). Then, composite sandwich panel was obtained.

The schematic of pyramidal unit cell is shown in Fig. 2. The relative density of the truss core is defined by the ratio of the truss volume to that of the unit cell, which is given by

$$
\bar{\rho}=\frac{\pi d^{2}}{\sin \omega(\sqrt{2} l \cos \omega+2 k)^{2}}
$$

where the geometrical parameters $d, l, k$ and $\omega$ are shown in Fig. 2. The distance between two closest struts is denoted by $k$. The $d, l$ and $\omega$ are the diameter, 
length and inclined angle of truss, respectively. In this paper, the geometrical parameters are taken as $d=2.5 \mathrm{~mm}, k=7 \mathrm{~mm}, l=21.2 \mathrm{~mm}$ and $\omega=45^{\circ}$. Therefore, the height of the core $H_{c}=l \sin \omega=15 \mathrm{~mm}$, the length of the core $L=\sqrt{2} l \cos \omega+2 k=35.2 \mathrm{~mm}$, the width of the core $W=\sqrt{2} l \cos \omega+2 k=35.2 \mathrm{~mm}$, and the relative density of the truss core is $2.24 \%$.

\section{Experimental methods}

In order to study the effect of thermal exposure on the indentation behaviors and failure mechanism of CFRPCSP with pyramidal truss cores, the specimens were exposed to different temperatures for $6 \mathrm{~h}$ before indentation test. An insulated temperature-controlled air oven was used to provide high temperature environments. The selected thermal exposure temperature was $20^{\circ} \mathrm{C}$ (room temperature), $100^{\circ} \mathrm{C}$, $150^{\circ} \mathrm{C}, 200^{\circ} \mathrm{C}, 250^{\circ} \mathrm{C}$ and $280^{\circ} \mathrm{C}$, respectively. This temperature regime may be experienced by the FRP system in an actual fire situation [19]. After each thermal exposure, the specimens were cooled at room temperature for a period more than $24 \mathrm{~h}$. Subsequently, quasi-static indentation tests were performed at room temperature. The schematic of the test procedure is presented in Fig. 3. The quasi-static indentation tests were conducted on INSTRON 5569 testing machine according to ASTM D6264/6264M [25]. Fig. 4 shows the test schematic of composite sandwich panel under indentation loading. In these tests, composite sandwich panel was supported by a rigid substrate. The indentation load was applied by a steel spherical indenter, and the indenter moved down to indent the specimen at a constant indenter displacement rate of $0.5 \mathrm{~mm} / \mathrm{min}$. The indenter was located in the center of the specimen, as shown in Fig. 5. In order to ensure the repeatability of the experimental results, three specimens were tested for each case. Composite sandwich panel for indentation test has $3 \times 3$ unit cell.

\section{Results and discussion}

\subsection{Thermal analysis of epoxy resin}

The mechanical property of FRP composites at high temperature is significantly 
dependent on the matrix property. Thus, the high temperature degradation behavior of epoxy resin matrix should be investigated firstly, which can aid the understanding of indentation responses of composite sandwich panel after thermal exposure. Thermal decomposition of epoxy resin matrix was measured by thermogravimetric analysis (TGA). The TGA was performed in air at heating rate of $20^{\circ} \mathrm{C} / \mathrm{min}$. The remanent mass-temperature curve for epoxy resin matrix is presented in Fig. 6. The curve was used to determine the range of temperature over which decomposition occurred. It can be found that the decomposition occurred in two main stages. In the first stage, the rapid degradation started from $250^{\circ} \mathrm{C}$ and then ended by a pseudo-plateau. In the second stage, the start point of rapid degradation was about $450{ }^{\circ} \mathrm{C}$, and the remanent mass dropped to near zero when the temperature increased to $600^{\circ} \mathrm{C}$. The reduction in mass was mainly due to the thermal decomposition of epoxy resin matrix at high temperature.

\subsection{Failure mechanism}

After thermal exposure, quasi-static indentation tests of composite sandwich panel were carried out at room temperature. Some damage mechanisms will initiate and propagate in composite sandwich panel under indentation loading [26-29]. The deformation history of composite sandwich panel was recorded during testing. Fig. 7 shows the deformation history of composite sandwich panel exposed to $20^{\circ} \mathrm{C}$. It can be seen that the deformation of the top face sheet increased as indentation displacement increased. At the same time, some damages occurred in top face sheet and extended as indentation displacement increased, which was accompanied by durative node failure. When the indentation displacement increased to a definite magnitude, the top face sheet was partially penetrated, and composite sandwich panel lost load supporting capability. The deformation of the top face sheet decreased rapidly after the occurrence of partial penetration, as shown in Fig. 7(f). The same deformation history was also observed for composite sandwich panels exposed to $100^{\circ} \mathrm{C}, 150^{\circ} \mathrm{C}$ and $200^{\circ} \mathrm{C}$, and thus the results were not presented here due to the limit of space.

The different deformation modes were observed under indentation loading for 
composite sandwich panels exposed to $250{ }^{\circ} \mathrm{C}$ and $280{ }^{\circ} \mathrm{C}$. Fig. 8 shows the deformation history of composite sandwich panel exposed to $250{ }^{\circ} \mathrm{C}$. The local deformation under the indenter was observed from the beginning of indentation test. As the indentation displacement increased, the fiber fracture and delamination occurred under the indenter. Subsequently, the delamination propagated in the top face sheet, which was accompanied by continue node failure. When the indentation displacement increased to a definite magnitude, the delamination and buckling failure of truss cores occurred, and severe delamination in the top face sheet was also observed, as shown in Fig. 8(f). Fig. 9 shows the deformation history of composite sandwich panel exposed to $280^{\circ} \mathrm{C}$. It can be seen that the delamination damage area was bigger than that of specimen exposed to $250^{\circ} \mathrm{C}$. The reasons for the occurrence of severe delamination failure are as follows. According to the results of the TGA, epoxy resin matrix experienced significant thermal decomposition when the specimens were exposed to $250^{\circ} \mathrm{C}$ and $280^{\circ} \mathrm{C}$ for $6 \mathrm{~h}$, which caused severe degradation of the matrix properties and fiber-matrix interface properties. Therefore, the severe delamination failure was observed under indentation loading in Figs. 8 and 9.

The effect of thermal exposure on the failure modes of the truss cores is presented in Fig. 10. The node failure was observed for the specimens exposed to 20-200 ${ }^{\circ}$, as shown in Fig. 10(a-d). However, the matrix properties and fiber-matrix interface properties experienced severe degradation when the exposure temperature was equal to $250^{\circ} \mathrm{C}$ and $280^{\circ} \mathrm{C}$. As a result, the ability of the resin to protect and unify the fibers, as well as transfer stress between fibers became lower [30]. Furthermore, the interfacial bonding strength was very weak. Therefore, the delamination and buckling failure was observed for the specimens exposed to $250^{\circ} \mathrm{C}$ and $280^{\circ} \mathrm{C}$, as shown in Fig. 10(e-f). In order to investigate the effect of thermal exposure on failure mechanism, scanning electron microscope (SEM) was used to examine the fiber-matrix interfaces of specimens. The SEM pictures of the fiber-matrix interfaces are shown in Fig. 11. Through comparing the test results in Fig. 11(a) with that in Fig. 11(b-c), it can be seen that the fibers were covered with matrix on the fracture surface as shown in Fig. 11(a), which indicated a good fiber-matrix adhesion for the specimen 
exposed to $20^{\circ} \mathrm{C}$. However, the fibers were separated from the matrix, and the residual matrix around the fibers was very little as shown in Fig. 11(b-c), which implied a weak fiber-matrix adhesion for the specimens exposed to $250^{\circ} \mathrm{C}$ and $280^{\circ} \mathrm{C}$.

\subsection{The indentation load}

Fig. 12 shows the indentation load of composite sandwich panel at different exposure temperatures. It can be found that the indentation load decreased as exposure temperature increased. The indentation load decreased significantly when the exposure temperature was equal to $250^{\circ} \mathrm{C}$ and $280^{\circ} \mathrm{C}$. Comparing with the specimen exposed to $20^{\circ} \mathrm{C}$, the indentation load of the specimen exposed to $280^{\circ} \mathrm{C}$ decreased by $78.74 \%$. This can be explained by the fact that the fiber-matrix interface was well bonded for the specimen exposed to $20^{\circ} \mathrm{C}$, as shown in Fig. 11(a). The matrix could effectively protect and unify the fiber, as well as transfer stress between fibers. In this case, the fibers could effectively carry the load, which provided the specimen high mechanical properties. As exposure temperature increased, some damages such as matrix micro-cracks, mass loss and thermal distortion occurred in the specimen [18,31], which caused the degradation of mechanical properties. At higher exposure temperature, the matrix experienced significant thermal decomposition, and the fiber-matrix interface properties became weaker, as shown in Fig. 11(b-c). The weak interface made the fibers debond easier from the matrix. Because of the degradation of the matrix properties and fiber-matrix interface properties, the ability of the resin to protect and unify the fiber, as well as transfer stress between fibers became lower. All these factors resulted in the heavy losses of the indentation load at higher exposure temperature.

\subsection{Energy absorption}

The effect of thermal exposure on the absorbed energy of composite sandwich panel was studied in this section. Fig. 13 shows a comparison of the absorbed energy at different exposure temperatures. In order to avoid inconsistencies, the absorbed energy was defined as the area under the load-displacement curve up to the ultimate failure load [26]. It can be found that the absorbed energy at failure decreased as exposure temperature increased, and the absorbed energy decreased by $72.37 \%$ as 
exposure temperature increased from $20^{\circ} \mathrm{C}$ to $280^{\circ} \mathrm{C}$. This is because the heat damage to resin matrix increased as exposure temperature increased, which reduced the ultimate failure load and indentation resistance capacity of composite sandwich panel. As a result, the area under load-displacement curve was smaller, and the absorbed energy was lower at higher exposure temperature. Especially when the exposure temperature was equal to $280^{\circ} \mathrm{C}$, the matrix properties and fiber-matrix interface properties experienced severe degradation, which significantly reduced the ultimate failure load and caused the lowest absorbed energy value.

\section{Conclusions}

The effect of thermal exposure on the indentation responses and energy absorption of CFRPCSP with pyramidal truss cores was investigated in this paper. Quasi-static indentation tests on composite sandwich panel revealed that the failure was dependent on the exposure temperature. The results showed that the indentation load and energy absorption decreased as exposure temperature increased. The severe reduction in indentation load and energy absorption was observed for the specimen exposed to $280^{\circ} \mathrm{C}$, which was mainly due to the degradation of the matrix properties and fiber-matrix interface properties at higher temperature. The effect of thermal exposure on failure modes was revealed as well. The top face sheet was partially penetrated for the specimens exposed to $20-200{ }^{\circ} \mathrm{C}$, while the top face sheet experienced severe delamination failure for the specimens exposed to $250^{\circ} \mathrm{C}$ and $280^{\circ} \mathrm{C}$. The truss cores also experienced different degrees of damage. The node failure was observed for the specimens exposed to $20-200^{\circ} \mathrm{C}$, while the delamination and buckling failure was also observed for the specimens exposed to $250^{\circ} \mathrm{C}$ and $280^{\circ} \mathrm{C}$. SEM pictures showed that the fiber-matrix interface properties strongly depended on the exposure temperature, and the severe degradation was observed for the specimens exposed to $250^{\circ} \mathrm{C}$ and $280^{\circ} \mathrm{C}$.

\section{Acknowledgements}

The present work is supported by National Science Foundation of China under Grant No. 11402094, the China Postdoctoral Science Foundation under Grant No. 
2015M572132, and the Fundamental Research Funds for the Central Universities, HUST: 2015QN015.

\section{References}

[1] S. Yin, L.Z. Wu, L. Ma, N. Steven, Hybrid truss concepts for carbon fiber composite pyramidal lattice structures, Compos. Part B 43(2012) 1749-1755.

[2] J. Xiong, L. Ma, S.D. Pan, L.Z. Wu, J. Papadopoulos, A. Vaziri, Shear and bending performance of carbon fiber composite sandwich panels with pyramidal truss cores, Acta. Mater. 60(2012) 1455-1466.

[3] H.L. Fan, W. Yang, Q. Zhou, Experimental research of compressive responses of multi-layered woven textile sandwich panels under quasi-static loading, Compos. Part B 42(2011) 1151-1156.

[4] B. Wang, L.Z. Wu, L. Ma, Y.G. Sun, S.Y. Du, Mechanical behavior of the sandwich structures with carbon fiber-reinforced pyramidal lattice truss core, Mater. Des. 31(2010) 2659-2663.

[5] F. Mujika, J. Pujana, M. Olave, On the determ ination of out-of-plane elastic properties of honeycomb sandwich panels, Polym. Test. 30(2011) 222-228.

[6] Y. Pourvais, P. Asgari, A.R. Moradi, O. Rahmani, Experimental and finite element analysis of higher order behaviour of sandwich beams using digital projection moiré, Polym. Test. 38(2014) 7-17.

[7] J.J. Zheng, L. Zhao, H.L. Fan, Energy absorption mechanisms of hierarchical woven lattice composites, Compos. Part B 43(2012) 1516-1522.

[8] Q. Zheng, H.L. Fan, J. Liu, Y. Ma, L. Yang, Hierarchical lattice composites for electromagnetic and mechanical energy absorptions, Compos. Part B 53(2013) 152-158.

[9] H.L. Fan, Q. Zhou, W. Yang, J.J. Zheng, An experiment study on the failure mechanisms of woven textile sandwich panels under quasi-static loading, Compos. Part B 41(2010) 686-692.

[10] K. Finnegan, G. Kooistra, H.N.G. Wadley, V.S. Deshpande, The compressive response of carbon fiber composite pyramidal truss sandwich cores, Int. J. Mater. Res. 98(2007) 1264-1272.

[11] H.L. Fan, L. Yang, F.F. Sun, D.N. Fang, Compression and bending performances of carbon fiber reinforced lattice-core sandwich composites, Compos. Part A 52(2013) 118-125.

[12] Y.G. Sun, L. Gao, Structural responses of all-composite improved-pyramidal truss 
sandwich cores, Mater. Des. 43(2013) 50-58.

[13] J. Xiong, L. Ma, L.Z. Wu, B. Wang, A. Vaziri, Fabrication and crushing behavior of low density carbon fiber composite pyramidal truss structures, Compos. Struct. 92(2010) 2695-2702.

[14] J. Kim, W.I. Lee, S.W. Tsai, Modeling of mechanical property degradation by short-term aging at high temperatures, Compos. Part B 33(2002) 531-543.

[15] J.Y. Liu, Z.G. Zhou, L. Ma, J. Xiong, L.Z. Wu, Temperature effects on the strength and crushing behavior of carbon fiber composite truss sandwich cores, Compos. Part B 42(2011) 1860-1866.

[16] P. Gu, R.J. Asaro, Distortion of polymer matrix composite panels under transverse thermal gradients, Compos. Struct. 82(2008) 413-421.

[17] L. Liu, J.W. Holmes, G.A. Kardomateas, V. Burman, Compressive response of composites under combined fire and compression loading. In: Proceedings of the 4th conference on composites in fire, Newcastle-upon-Tyne, UK, 15-16 September 2005.

[18] J. Wolfrum, S. Eibl, L. Lietch, Rapid evaluation of long-term thermal degradation of carbon fiber epoxy composites, Compos. Sci. Technol. 69(2009) 523-530.

[19] S.K. Foster, L.A. Bisby, High temperature residual properties of externally bonded FRP systems. In: Proceedings of the 7th international symposium on fiber reinforced polymer reinforcement for reinforced concrete structures (FRPRCS-7), SP-230-70, New Orleans, 7-10 November, 2005, pp.1235-1252.

[20] J.A. Milke, A.J. Vizzini, Thermal response of fiber-exposed composites, J. Compos. Technol. Res. 13(1991) 145-151.

[21] L. Mascia, J. Zhang, Mechanical properties and thermal aging of a perfluoroether-modified epoxy resin in castings and glass fiber composites, Compos. 26(1995) 379-385.

[22] I. Ammar-Khodja, C. Picard, M. Fois, P. Netchitaïlo, Preliminary results on thermo-oxidative ageing of multi-hole carbon/epoxy composites, Compos. Sci. Technol. 69(2009) 1427-1431.

[23] W. Fan, J.L. Li, Y.Y. Zheng, Improved thermo- oxidative stability of three-dimensional and four-direction al braided carbon fi ber/epoxy hierarchical composites using graphene-reinforced gradient interface layer, Polym. Test. 44(2015) 177-185.

[24] D.B. Cleary, C.D. Cassino, R. Tortorice, Effect of elevated temperatures on a 
fiber composite to strengthen concrete columns, J. Reinf. Plast. Compos. $22(2003) 881-895$.

[25] ASTM: D6264/D6264M. Standard test method for measuring the damage resistance of a fiber-reinforced polymer-matrix composite to a concentrated quasi-static indentation force, West Conshohocken (PA): ASTM Int.; 2012.

[26] G. Zhou, M. Hill, N. Hookham, Investigation of parameters governing the damage and energy absorption characteristics of honeycomb sandwich panels. J. Sandwich. Struct. Mater. 9(2007) 309-342.

[27] L. Du, G.Q. Jiao, Indentation study of Z-pin reinforced polymer foam core sandwich structures, Compos. Part A 40(2009) 822-829.

[28] D. Ruan, G.X. Lu, Y.C. Wong, Quasi-static indentation tests on aluminium foam sandwich panels, Compos. Struct. 92(2010) 2039-2046.

[29] E.A. Flores-Johnson, Q.M. Li, Experimental study of the indentation of sandwich panels with carbon fiber-reinforced polymer face sheets and polymeric foam core, Compos. Part B 42(2011) 1212-1219.

[30] S.H. Cao, Z.S. Wu, X. Wang, Tensile properties of CFRP and hybrid FRP composites at elevated temperatures, J. Compos. Mater. 43(2009) 315-330.

[31] L.J. Burcham, R.F. Eduljee, J.W. Gillespie, Investigation on the microcracking behavior of bismalei-mide composites: during thermal aging, Polym. Compos. 16(1995) 507-517. 


\section{Figure caption}

Fig. 1. Illustration of the manufacturing route for making composite sandwich panel with pyramidal truss cores: (a) the composite struts were inserted into the holes of the molds; (b) the ends of composite struts were dispersed and embedded into the face sheets; (c) the preformed sandwich panel was cured; (d) the molds were removed from the specimen after curing.

Fig. 2. The schematic of the unit cell of the pyramidal truss core.

Fig. 3. Schematic of the test procedure: (a) specimen was exposed to high temperature; (b) specimen was cooled at room temperature; (c) specimen was tested at room temperature under indentation loading.

Fig. 4. The test schematic of composite sandwich panel under indentation loading.

Fig. 5. The schematic of the indenter position.

Fig. 6. TGA curve for epoxy resin.

Fig. 7. The deformation history of composite sandwich panel under indentation loading after exposure at $20^{\circ} \mathrm{C}$ for $6 \mathrm{~h}$.

Fig. 8. The deformation history of composite sandwich panel under indentation loading after exposure at $250^{\circ} \mathrm{C}$ for $6 \mathrm{~h}$.

Fig. 9. The deformation history of composite sandwich panel under indentation loading after exposure at $280^{\circ} \mathrm{C}$ for $6 \mathrm{~h}$.

Fig. 10. The failure modes of the truss cores under indentation loading after exposure at different temperatures for $6 \mathrm{~h}$ : (a) $20^{\circ} \mathrm{C}$; (b) $100^{\circ} \mathrm{C}$; (c) $150^{\circ} \mathrm{C}$; (d) $200^{\circ} \mathrm{C}$; (e) $250^{\circ} \mathrm{C}$; (f) $280^{\circ} \mathrm{C}$.

Fig. 11. SEM pictures of fiber-matrix interfaces of specimens: (a) interface with thermal exposure of $20^{\circ} \mathrm{C}$ for $6 \mathrm{~h}$; (b) interface with thermal exposure of $250^{\circ} \mathrm{C}$ for $6 \mathrm{~h}$; (c) interface with thermal exposure of $280^{\circ} \mathrm{C}$ for $6 \mathrm{~h}$.

Fig. 12. The failure load of composite sandwich panels at different exposure temperatures.

Fig. 13. The absorbed energy of composite sandwich panels at different exposure temperatures. 

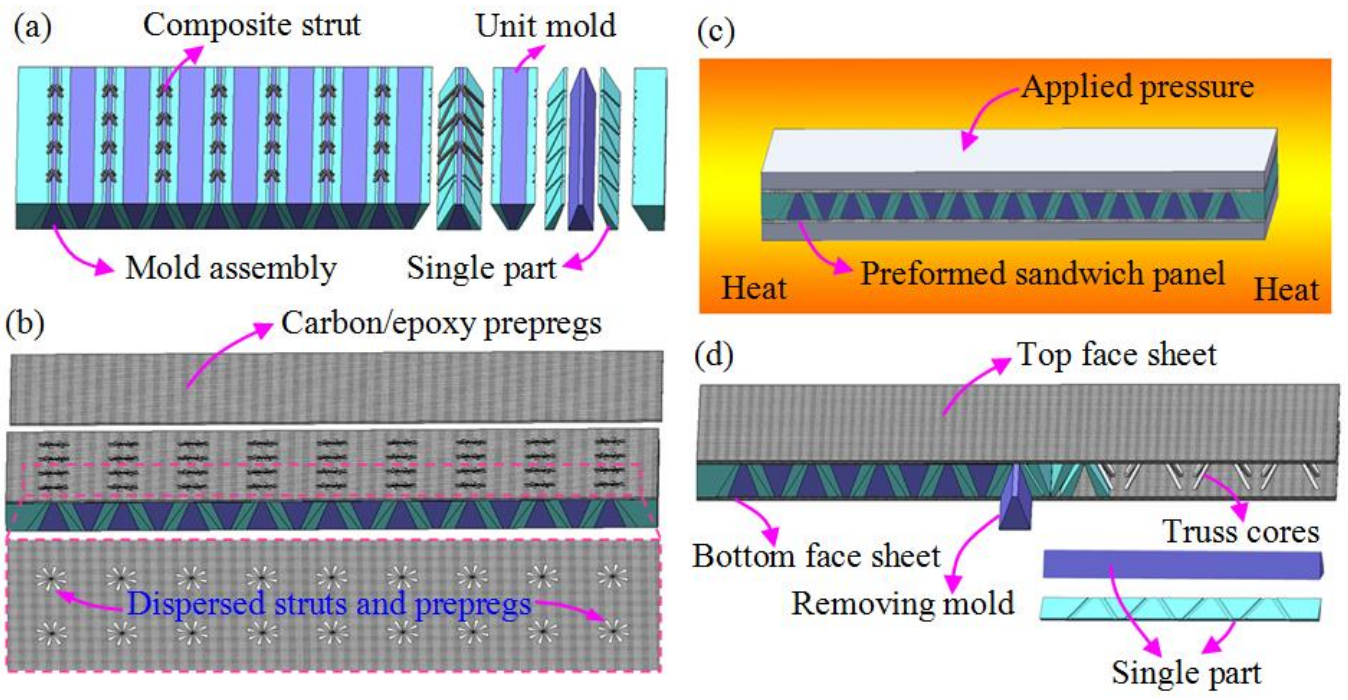

Fig. 1. Illustration of the manufacturing route for making composite sandwich panel with pyramidal truss cores: (a) the composite struts were inserted into the holes of the molds; (b) the ends of composite struts were dispersed and embedded into the face sheets; (c) the preformed sandwich panel was cured; (d) the molds were removed from the specimen after curing. 


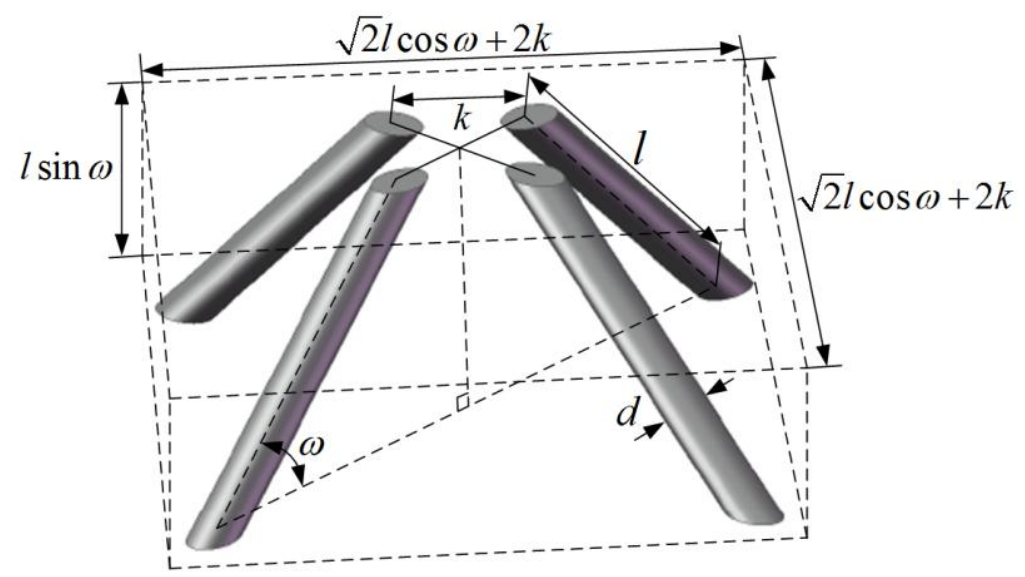

Fig. 2. The schematic of the unit cell of the pyramidal truss core. 
(a)

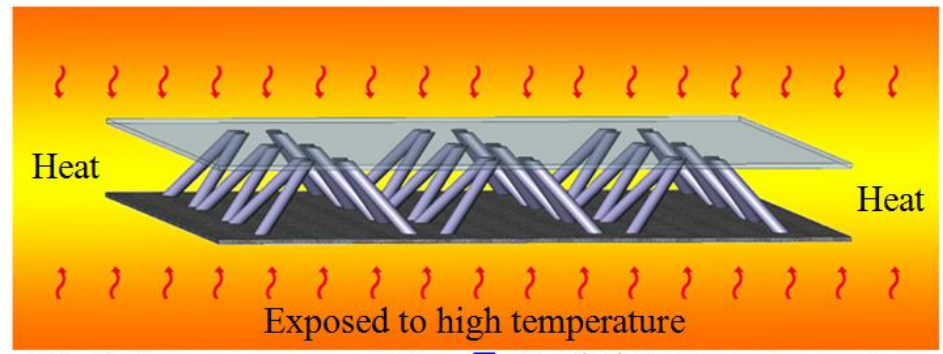

(b)

Cooled at room temperature Cooled at room temperature
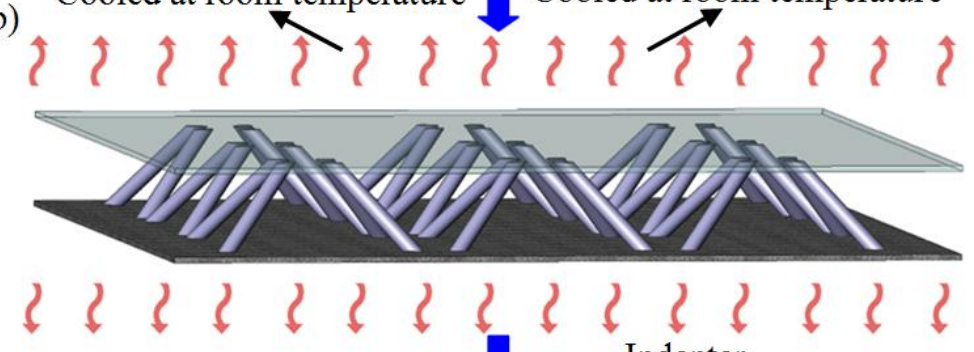

(c)

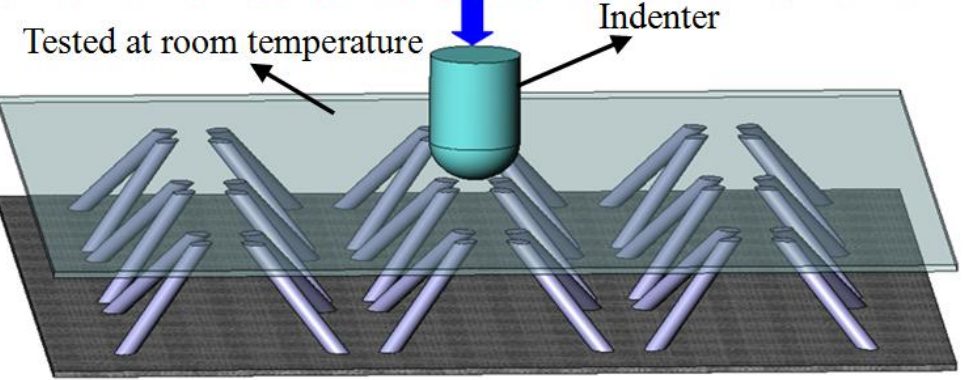

Fig. 3. The schematic of the test procedure: (a) specimen was exposed to high temperature; (b) specimen was cooled at room temperature; (c) specimen was tested at room temperature under indentation loading. 


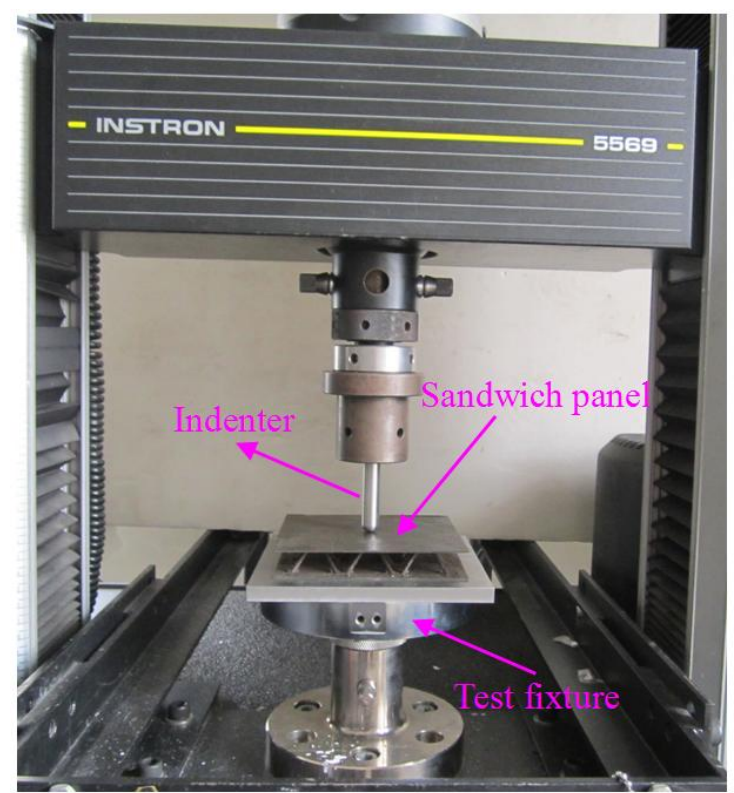

Fig. 4. The test schematic of composite sandwich panel under indentation loading. 


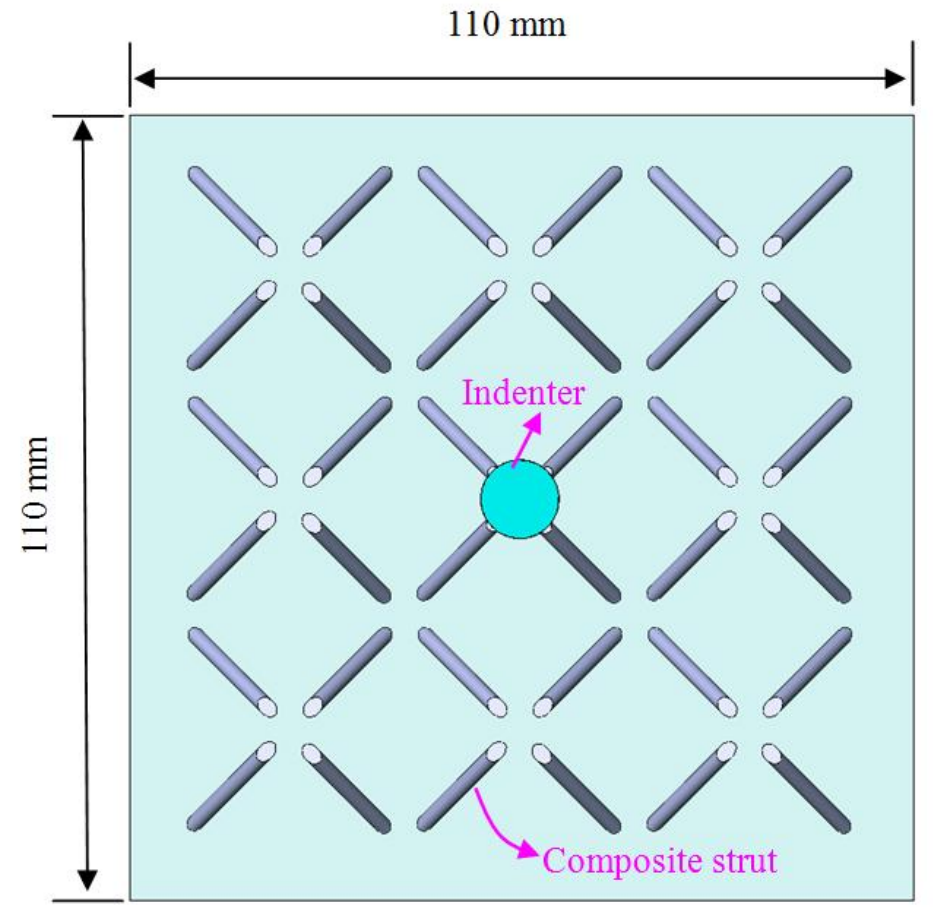

Fig. 5. The schematic of the indenter position. 


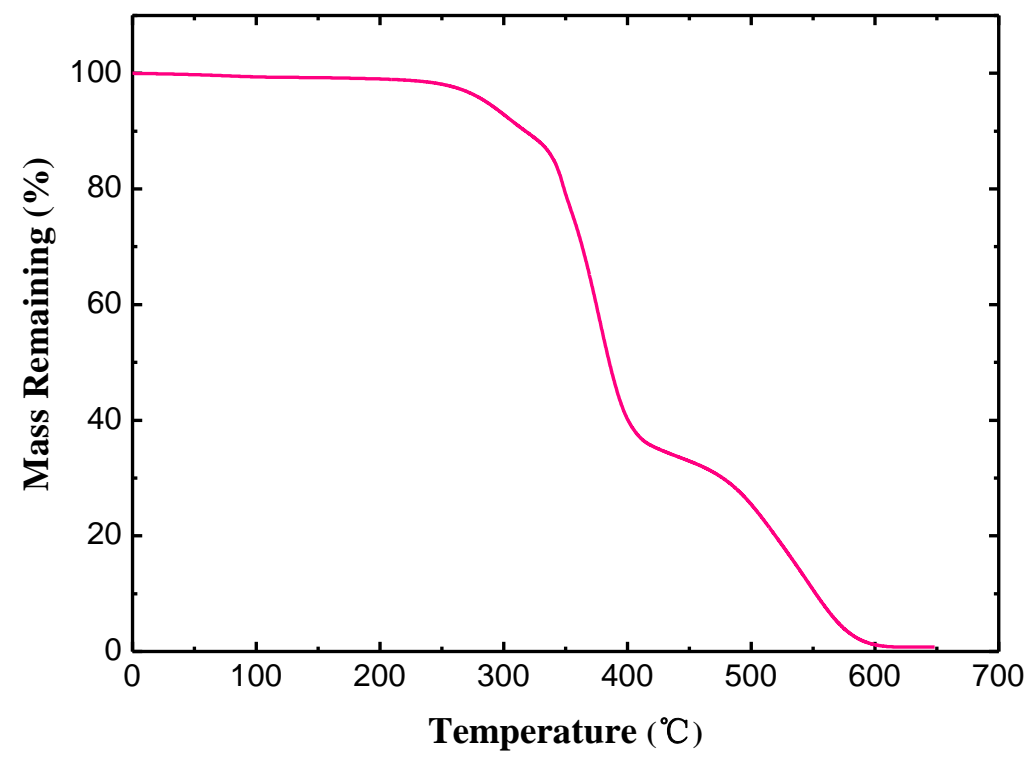

Fig. 6. TGA curve for epoxy resin. 

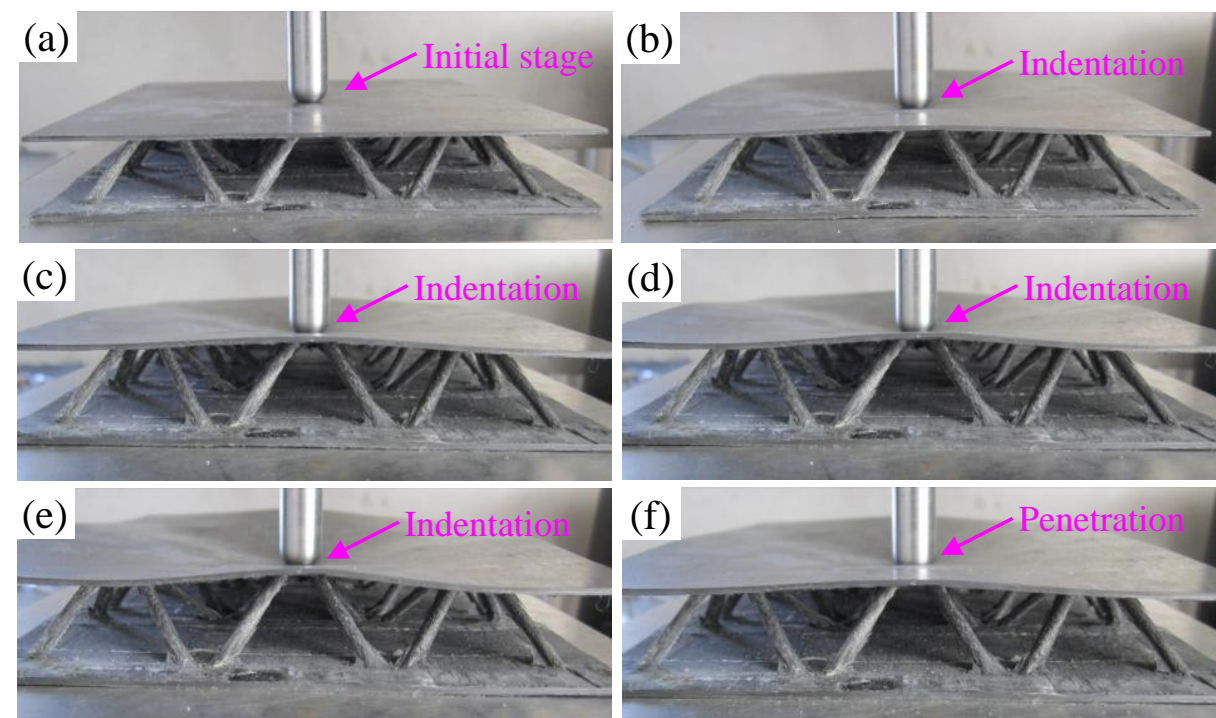

Fig. 7. The deformation history of composite sandwich panel under indentation loading after exposure at $20^{\circ} \mathrm{C}$ for $6 \mathrm{~h}$. 

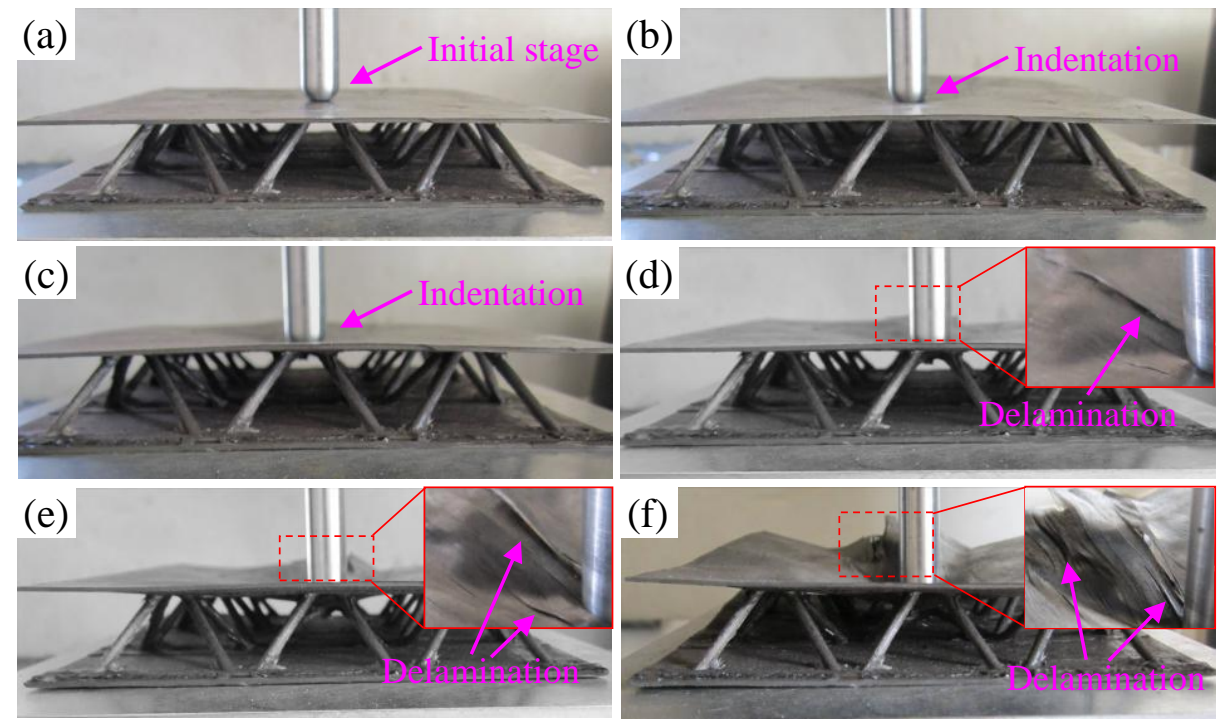

Fig. 8. The deformation history of composite sandwich panel under indentation loading after exposure at $250^{\circ} \mathrm{C}$ for $6 \mathrm{~h}$. 

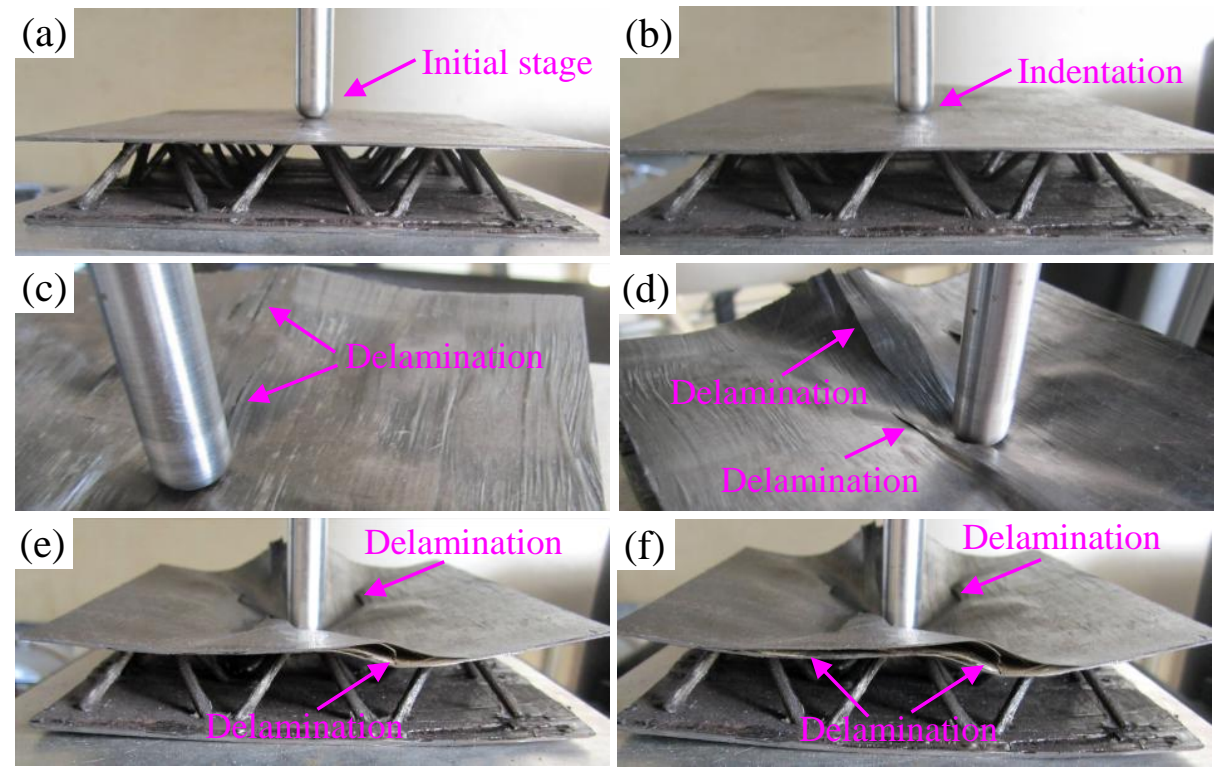

Fig. 9. The deformation history of composite sandwich panel under indentation loading after exposure at $280^{\circ} \mathrm{C}$ for $6 \mathrm{~h}$. 

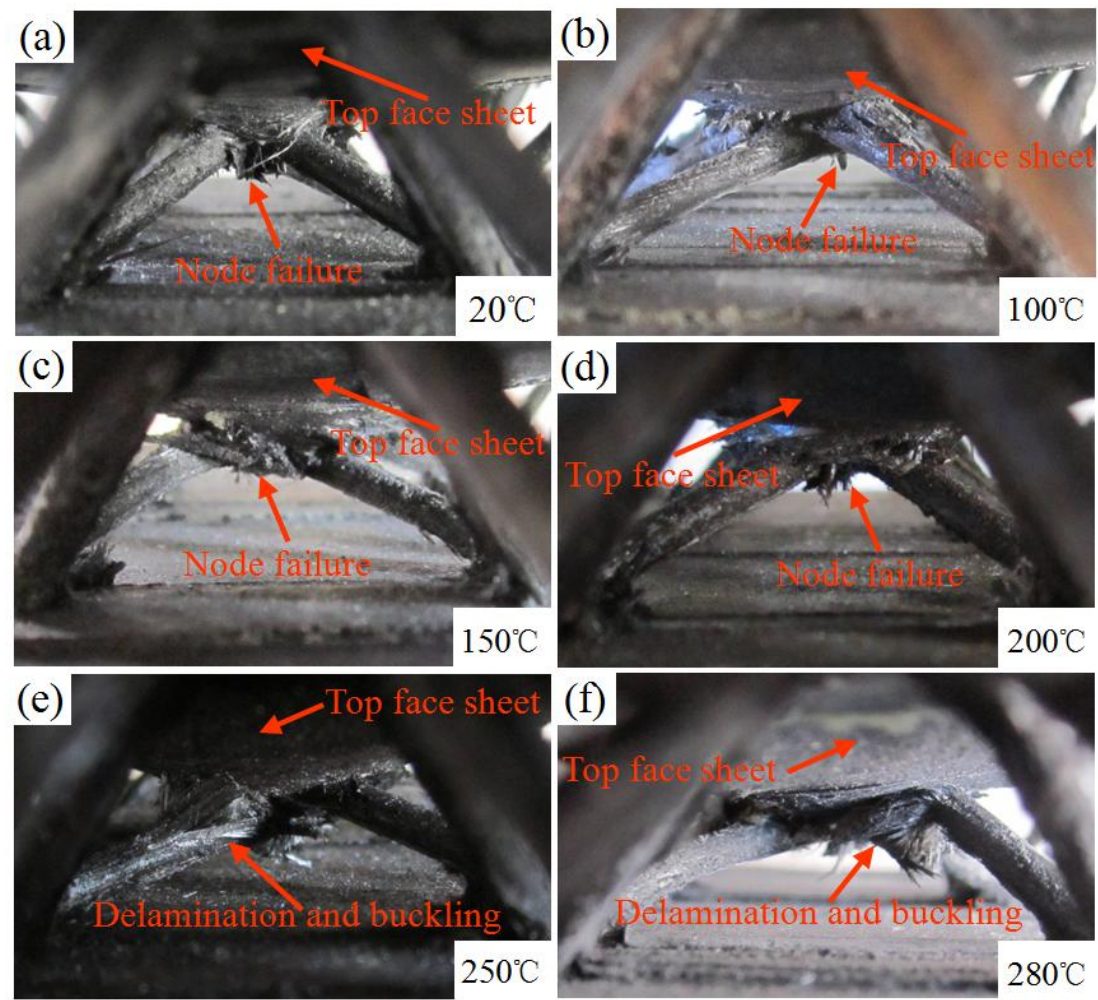

Fig. 10. The failure modes of the truss cores under indentation loading after exposure at different temperatures for $6 \mathrm{~h}$ : (a) $20^{\circ} \mathrm{C}$; (b) $100^{\circ} \mathrm{C}$; (c) $150^{\circ} \mathrm{C}$; (d) $200^{\circ} \mathrm{C}$; (e) $250^{\circ} \mathrm{C}$; (f) $280^{\circ} \mathrm{C}$. 


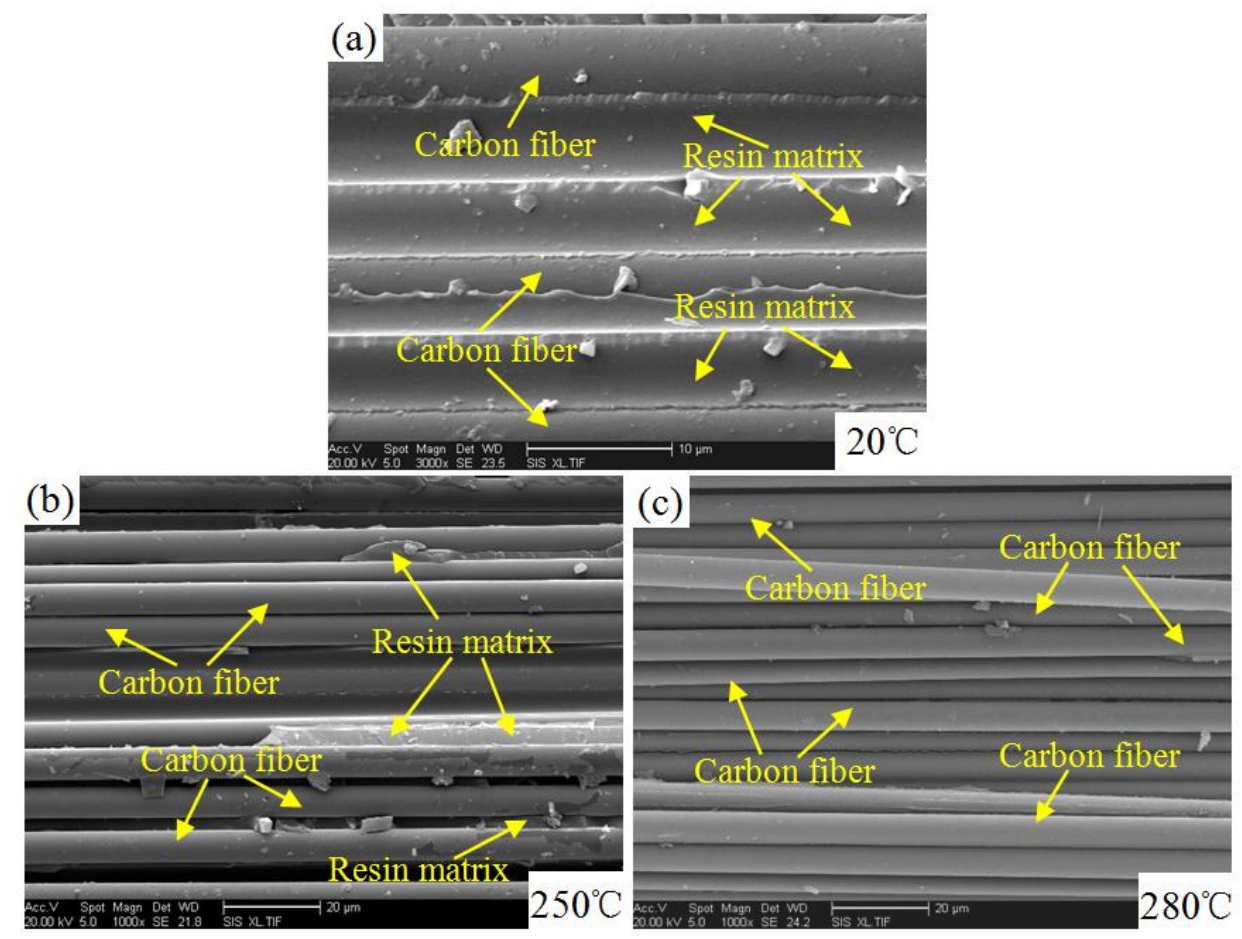

Fig. 11. SEM pictures of fiber-matrix interfaces of specimens: (a) interface with thermal exposure of $20^{\circ} \mathrm{C}$ for $6 \mathrm{~h}$; (b) interface with thermal exposure of $250^{\circ} \mathrm{C}$ for $6 \mathrm{~h}$; (c) interface with thermal exposure of $280^{\circ} \mathrm{C}$ for $6 \mathrm{~h}$. 


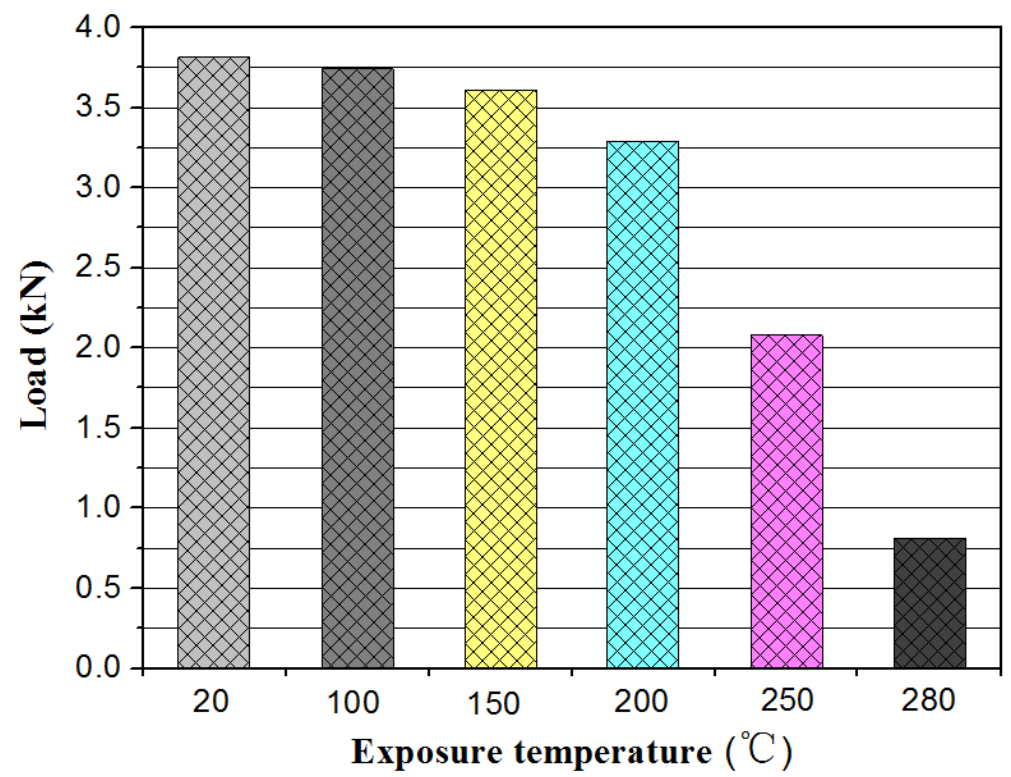

Fig. 12. The failure load of composite sandwich panels at different exposure temperatures. 


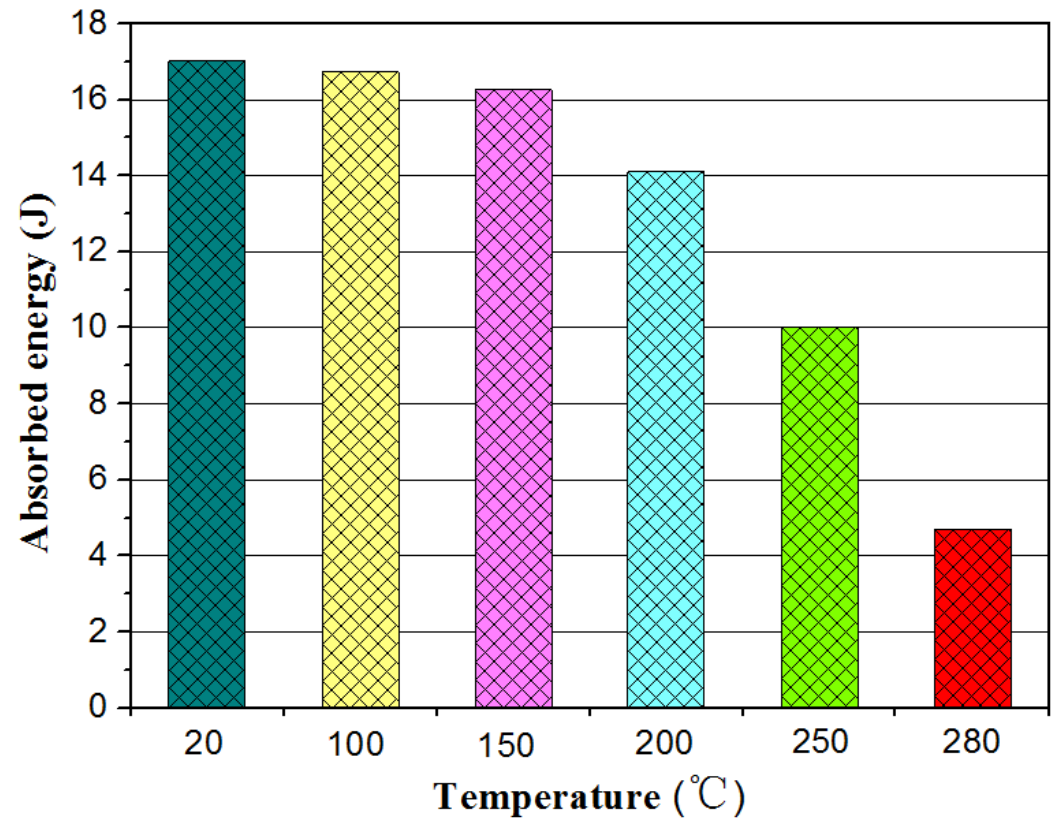

Fig. 13. The absorbed energy of composite sandwich panels at different exposure temperatures. 